\title{
Pacemaker-induced massive tricuspid regurgitation
}

\author{
(1) Mario Milun* \\ General Hospital "Dr. Tomislav \\ Bardek", Koprivnica, Croatia
}

KEYWORDS: tricuspid regurgitation, pacemaker

CITATION: Cardiol Croat. 2019;14(3-4):87. | https://doi.org/10.15836/ccar2019.87

*ADDRESS FOR CORRESPONDENCE: Mario Milun, Opća bolnica “Dr. Tomislav Bardek”, Željka Selingera bb, HR48000 Koprivnica, Croatia. / Phone: +385-99-332-4368 / E-mail: mariomilunee@gmail.com ORCID: Mario Milun, https://orcid.org/0000-0002-9535-6856

IIIIIIIIIIIIIIIIIIIIIIIIIIIIIIIIIIIIIIIIIIIIIIIIIIIIIIIIIIIIIIIIIIIIIIIIIIIIIIIIIIIIIIIIIIIIIIIIIIIIIIIIIIIIIIIIIIIII

Case report: Female patient was admitted to the Cardiology Department with the symptoms of inappetence, dyspnea, and acute heart failure. She was 83-year-old woman who had single chamber right ventricular pacemaker (PM) implanted in 2006 because of a complete AV block, and reimplanted again in 2014. She had a long history of hypertension, atrial fibrillation, and was diagnosed with pulmonary embolism in 2015. Upon admission she had a radiologically and clinically verified signs of heart failure. The ECG showed a permanent pacing. Echocardiogram verified preserved global and segmental left ventricular (LV) systolic function, with mild LV diastolic dysfunction. Systolic function of the right ventricle was normal, with dilatation of the right chambers of the heart. Tricuspid valvular ring was dilatated, and there was a "loop" of the pacemaker lead moving freely through the valve, with massive tricuspid regurgitation. Systolic pulmonary artery pressure was $45 \mathrm{mmHg}$. Patient was treated with diuretics and was soon clinically better. Because of her fragile health it was decided not to pursue cardiosurgical intervention, or to change the pacemaker lead.

Conclusion: A mild or moderate TR is a common echocardiographic finding in patients with PM and has been reported as high as 53\%. Such a prevalence of mild or moderate TR is expected since the lead crosses the tricuspid valve and may slightly impair its closure. Severe lead induced tricuspid regurgitation (LITR) is very rare. Usually results from implantation damage to tricuspid valve (perforation or laceration of the tricuspid leaflets) or lead interference with the tricuspid valve leaflets. It can also be due to an abnormal activation of the right ventricle with a delayed activation of the apex and the papillary muscles. Fibrosis adherences between lead and tricuspid valve have been described and may cause delayed severe TR. Diagnosis is based on symptoms, clinical examination, echocardiogram, cardiac CT, or MRI. Therapeutic approach can be conservative or surgical..$^{1-3}$
RECEIVED:

February 28, 2019

ACCEPTED:

March 24, 2019

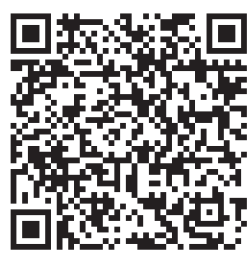

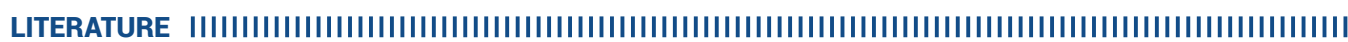

1. Loupy A, Messika-Zeitoun D, Cachier A, Himbert D, Brochet E, Lung B, et al. An unusual cause of pacemaker-induced severe tricuspid regurgitation. Eur J Echocardiogr. 2008 Jan;9(1):201-3. https://doi.org/10.1093/ejechocard/jem071

2. Lin G, Nishimura RA, Connolly HM, Dearani JA, Sundt TM 3rd, Hayes DL. Severe symptomatic tricuspid valve regurgitation due to permanent pacemaker or implantable cardioverter-defibrillator leads. J Am Coll Cardiol. 2005 May 17;45(10):1672-5. https://doi.org/10.1016/j.jacc.2005.02.037

3. Paniagua D, Aldrich HR, Lieberman EH, Lamas GA, Agatston AS. Increased prevalence of significant tricuspid regurgitation in patients with transvenous pacemakers leads. Am J Cardiol. 1998 Nov 1;82(9):1130-2, A9. https://doi.org/10.1016/S0002-9149(98)00567-0 